\title{
A FLUORESCENCE QUENCHING METHOD FOR DETERMINATION OF COPPER IONS WITH CDTE QUANTUM DOTS
}

\author{
YILIN WANG, JIANPING LU, ZHANGFA TONG, HAIFENG HUANG \\ College of Chemistry and Chemical Engineering, Guangxi University, Nanning 530004, PR China
}

(Received: March 2, 2009 - Accepted: May 29, 2009)

\begin{abstract}
CdTe quantum dots (QDs) were synthesized in aqueous medium by employing L-cysteine as a stabilizer. They exhibited high stability and moderate fluorescence quantum yield (12.5\%), and were characterized by UV-vis absorption, fluorescence spectra, Fourier transform infrared spectrometry. Based upon the fact that the fluorescence of the QDs could be quenched by $\mathrm{Cu}^{2+}$, a simple and rapid method for $\mathrm{Cu}^{2+}$ detection was proposed using L-cysteine-capped CdTe QDs as fluorescent probes. Under optimum conditions, the response showed linear proportion to the concentration of $\mathrm{Cu}^{2+}$ between 20 to $300 \mu \mathrm{g} \cdot \mathrm{L}^{-1}$. The detection limit was $9.3 \mu \mathrm{g} \cdot \mathrm{L}^{-1}$. This method was successfully applied to the determination of trace copper in real samples.
\end{abstract}

Keywords: CdTe, Quantum dots, Fluorescence quenching, Copper ions

\section{INTRODUCTION}

Luminescent semiconductor quantum dots (QDs) is a novel fluorescence nano-material, which have gained increasing attention in the past decades. Compared with conventional organic dyes, QDs have some unique optical and electronic properties, such as broad excitation spectra, narrow, tunable and symmetric emission spectra, and highly stability against photobleaching 1,2. The studies on QDs mainly focused on developing new techniques to synthesize high-quality QDs ${ }^{3-5}$ and expanding the application areas, such as in material, biological and medical fields ${ }^{6-8}$. The effect of ionic species on the luminescence of QDs was also studied. For example, Henglein ${ }^{9}$ reported that cadmium ions increased the luminescence quantum yield of CdS nanoparticles by about $50 \%$ in an alkaline solution. Kotov et al ${ }^{10}$ found that $\mathrm{MoS}_{4}^{-}$bound to the surface of CdS nanoparticles induced enhancement of their excitonic emission. Weller et al ${ }^{11}$ showed that the emission intensity of CdTe nanocrystals stabilized by thioglycolic acid increased as $\mathrm{pH}$ decreased. In contrast, some ionic species quench the luminescence of semiconductor nanoparticles. Copper ions quenching the emission of thioglycerol-capped CdS QDs was first reported by Chen ${ }^{12}$. Since then, the use of QDs as fluorescence probes for ions sensing has received considerable attention, a few reports based on QDs fluorescence quenching for the determination of heavy metal ions have been published. Among them, CdS QDs as luminescence probes was widely studied. For example, Kerim et al ${ }^{13}$ described the optical detection of $\mathrm{Cu}^{2+}$ and $\mathrm{Ag}^{+}$with peptide-coated CdS QDs. Yan and Zhu's groups ${ }^{14,15}$ presented the optical detection of $\mathrm{Hg}^{2+}$ and $\mathrm{Ag}^{+}$with L-cysteine-capped CdS QDs, respectively. Recently, CdTe QDs as luminescence probes for determination of $\mathrm{Pb}^{2+}$ and $\mathrm{Hg}^{2+}$ were also reported ${ }^{16,17}$.

Copper is one of essential elements for all living organisms. Many analytical methods, such as atomic absorption spectrometry, spectrophotometry, inductively coupled plasma atomic emission spectrometry, and electrochemical methods, have been applied to copper determination. Of them, spectrofluorimetry with fluorescent probes has now obtained the attention of many researchers. QDs are one of the fluorescent probes. Specially, the three QDs, CdSe/ZnS modified with bovine serum albumin(BSA) ${ }^{18}$, CdSe modified with 2-mercaptoethane sulphonic acid(MESA) ${ }^{19}$ and $\mathrm{CdSe} / \mathrm{CdS}$ coreshell coated with L-cysteine ${ }^{20}$, have been employed, respectively. For CdSe/ $\mathrm{ZnS}$ modified with BSA, it showed detection limit as low as $10 \mathrm{nM}$ for $\mathrm{Cu}^{2+}$, unfortunately, real sample analysis has not been reported. With the detection limit of $0.2 \mu \mathrm{g} \cdot \mathrm{L}^{-1}, \mathrm{CdSe}$ modified with MESA was used to determine $\mathrm{Cu}^{2+}$ in water. The content of copper in vegetable samples was determined using $\mathrm{CdSe} /$ CdS coated with L-cysteine as fluorescence probe. However, the QDs used in these papers were synthesized via organometallic routes which were cost and required special reaction conditions. Moreover, a further process is needed for the QDs used in aqueous solution because as-prepared QDs often prefer to disperse in nonpolar organic solvents. The aim of this work is to synthesize water-soluble CdTe QDs capped with L-cysteine in aqueous solution through a straightforward one-pot process using safe and low-cost inorganic salts as precursors, and to develop a simple method for the detection of $\mathrm{Cu}^{2+}$ based on fluorescence quenching effect.

\section{EXPERIMENTAL}

\section{Apparatus}

The $\mathrm{pH}$ value was controlled with a $\mathrm{pHs}-3 \mathrm{C}$ digital $\mathrm{pH}$ meter. The fluorescence measurements were conducted on a 960CRT spectrofluorophotometer. Absorption spectra were taken with a UV-2102 spectrometer. FT-IR spectra were recorded on a Nexus-470 spectrometer. The quantum yield (QY) at room temperature was measured using Rhodamine6G $(\mathrm{QY}=95 \%)$ in ethanol as a reference. The determination of copper in samples was achieved by an Optima 5300DV ICP-OES spectrometer.

\section{Reagents}

Cadmium chloride hemidihydrate $(99.0 \%$, Damao Chemical Reagent Factory, Tianjin, China), L-Cysteine hydrochloride monohydrate $(99.0 \%$, Sinopharm Chemical Reagent Co.Ltd, Shanghai, China), tellurium powder (99.99\%, Delan Chemical Plant, Tianjin, China), sodium borohydride $(96 \%$, Shanghai JingHua Scientific \& Technological Research Institute) and sodium hydroxide ( $96 \%$, Shanghai Chemical Reagent Co.Ltd) were used as received without any further purification. Standard stock solution of $\mathrm{Cu}^{2+}\left(1.0 \mathrm{mg} \cdot \mathrm{mL}^{-1}\right)$ was prepared by dissolving $\mathrm{CuCl}_{2} \cdot 2 \mathrm{H}_{2} \mathrm{O}$ (Guanghua Chemical Factory Co.Ltd, Guangdong, China). The standard solution of $\mathrm{Cu}^{2+}$ was obtained by serial dilution of $1 \mathrm{mg} \cdot \mathrm{mL}^{-1} \mathrm{Cu}^{2+}$ to $2 \mathrm{mg} \cdot \mathrm{L}^{-1}$. $\mathrm{Na}_{2} \mathrm{HPO}_{4}-\mathrm{KH}_{2} \mathrm{PO}_{4}$ buffer was prepared by mixing $1 / 15 \mathrm{~mol} \cdot \mathrm{L}^{-1}$ of $\mathrm{Na}_{2} \mathrm{HPO}_{4}$ solution and $1 / 15 \mathrm{~mol} \cdot \mathrm{L}^{-1}$ of $\mathrm{KH}_{2} \mathrm{PO}_{4}$ solution to the required $\mathrm{pH}$ value.

Doubly deionized water (DDW) was used throughout.

\section{Synthesis of CdTe QDs capped with L-cysteine}

The CdTe QDs was synthesized according to the procedure described in the literature ${ }^{21,22}$. Briefly, sodium borohydride of $160 \mathrm{mg}$ was transferred to a small flask, then, DDW of $2.0 \mathrm{~mL}$ was added. After tellurium powder of $255 \mathrm{mg}$ was added in the flask, the reaction system was cooled by ice. During the reaction, a small outlet connected to the flask was kept open to release the pressure from the resulting hydrogen. After approximately $5 \mathrm{~h}$, the black tellurium powder disappeared and sodiumtetraborate white precipitate appeared on the bottom of the flask nevertheless. The resulting NaHTe in clear supernatant was used in the preparation of CdTe QDs.

For the preparation of CdTe capped with L-cysteine, $\mathrm{CdCl}_{2} \cdot 2.5 \mathrm{H}_{2} \mathrm{O}$ of $0.5450 \mathrm{~g}$ was dissolved in $125 \mathrm{~mL}$ water, and L-cysteine hydrochloride monohydrate of $1.0052 \mathrm{~g}$ was added under stirring, followed by adjusting the $\mathrm{pH}$ to 11.2 with $\mathrm{NaOH}$ solution of $1 \mathrm{~mol} \cdot \mathrm{L}^{-1}$. The solution was placed in a threenecked flask fitted with a septum and valves and was deaerated by $\mathrm{N}_{2}$ bubbling for $30 \mathrm{~min}$. Under stirring, freshly prepared oxygen-free $\mathrm{NaHTe}$ solution of $1.0 \mathrm{~mL}$ was injected into the flask. After deaerated for another $30 \mathrm{~min}$, the reaction mixture was refluxed at $100^{\circ} \mathrm{C}$ under open-air conditions for $30 \mathrm{~min}$.

Effect of pH on the fluorescence intensity of CdTe QDs

In seven $10.0 \mathrm{~mL}$ colorimetric tubes, $0.2 \mathrm{~mL}$ CdTe QDs of $1.36 \times 10^{-}$ ${ }^{5} \mathrm{~mol} \cdot \mathrm{L}^{-1}$ were added, respectively. Then, they were diluted to mark with a series of $\mathrm{Na}_{2} \mathrm{HPO}_{4}-\mathrm{KH}_{2} \mathrm{PO}_{4}$ buffers of $\mathrm{pH}$ values. The fluorescence spectra were recorded on a $960 \mathrm{CRT}$ spectrofluorophotometer, the slit widths of both excitation and emission were $10 \mathrm{~nm}$. 


\section{Samples preparation}

The preparation of samples was conducted according to the procedures described elsewhere ${ }^{23}$. Hair and tea were dried in an oven at $100^{\circ} \mathrm{C}$ to obtain a constant weight. $2.000 \mathrm{~g}$ hair or tea sample was weighed and transferred into a crucible. After the sample was ashed on hot plate, it was incinerated in Muffle furnace at $620^{\circ} \mathrm{C}$ for about 4 hours until the sample turned into white color. After the crucible cooled to room temperature, $5.0 \mathrm{~mL} \mathrm{HCl}$ of $6 \mathrm{~mol} \cdot \mathrm{L}^{-1}$ and 0.2 $\mathrm{mL} \mathrm{H}_{2} \mathrm{O}_{2}$ of $30 \%$ were added, respectively. The mixture was evaporated to almost dry, then $5.0 \mathrm{~mL} \mathrm{HCl}$ of $6 \mathrm{~mol} \cdot \mathrm{L}^{-1}$ was added. After the solid dissolved completely, the $\mathrm{pH}$ value was adjusted to 7.0 with $\mathrm{NaOH}$ solution of. $1 \mathrm{~mol} \cdot \mathrm{L}^{-1}$. Finally, the solution was diluted with DDW to $100 \mathrm{~mL}$.

\section{Determination of $\mathrm{Cu}^{2+}$}

For determining the concentration of $\mathrm{Cu}^{2+}, 0.2 \mathrm{~mL}$ CdTe QDs solution of $1.36 \times 10^{-5} \mathrm{~mol} \cdot \mathrm{L}^{-1}, 2.0 \mathrm{~mL} \mathrm{Na} \mathrm{HPO}_{4}-\mathrm{KH}_{2} \mathrm{PO}_{4}$ buffer solution $1 / 15 \mathrm{~mol} \cdot \mathrm{L}^{-1}$ $(\mathrm{pH}=7.2)$ and different amounts of $\mathrm{Cu}^{2+}$ standard solutions $\left(2.0 \mathrm{mg} \cdot \mathrm{L}^{-1}\right)$ were sequentially added into $10.0 \mathrm{~mL}$ colorimetric tubes which were shaken thoroughly afterwards. After the tubes were kept at room temperature for $15 \mathrm{~min}$, the mixture was diluted to the mark with buffer solution. The fluorescence intensity was measured at $\lambda_{\mathrm{ex}} / \lambda_{\mathrm{em}}=365 / 550 \mathrm{~nm}$, the slit widths of both excitation and emission were $10 \mathrm{~nm}$

\section{RESULTS AND DISCUSSION}

\section{Characterization of CdTe QDs capped with L-cysteine}

The CdTe QDs solution, if kept in a refrigerator, was stable for months. Moreover, the quantum yield can reach as high as $12.5 \%$. The absorption and fluorescence spectra of CdTe QDs were shown in Figure 1. A well-resolved absorption maximum of the first electronic transition suggested a sufficient narrow size distribution of the QDs. The diameter and the concentration of the QDs were determined using an empirical formula ${ }^{24}: D=9.8127 \times 10^{-7} \times$ $\lambda^{3}-1.7147 \times 10^{-3} \times \lambda^{2}+1.0064 \times \lambda-194.8, \varepsilon=10043 \times(D)^{2.12}$ and $A=\varepsilon b C$. Where $D(\mathrm{~nm})$ is the size of a given CdTe sample; $\lambda(\mathrm{nm})$ is the wavelength of the first excitonic absorption peak of the corresponding sample. $\varepsilon\left(\mathrm{L} \cdot \mathrm{mol}^{-}\right.$ $\left.{ }^{1} \cdot \mathrm{cm}^{-1}\right)$ is the extinction coefficient of CdTe QDs; $A$ is the absorbance at the peak position of the first exciton absorption peak; $b$ is the path length $(\mathrm{cm})$ of the radiation beam used for recording the absorption spectra, and $C$ is the molar concentration $\left(\mathrm{mol} \cdot \mathrm{L}^{-1}\right)$ of the QDs. The result showed that the particle diameter and the concentration of the QDs was approximately $3.0 \mathrm{~nm}$ and 1.36 $\times 10^{-5} \mathrm{~mol} \cdot \mathrm{L}^{-1}$, respectively. The emission peak located at $550 \mathrm{~nm}$, and it could be observed that the fluorescence spectra were symmetric with the FWHM (full width at half maximum) of about $60 \mathrm{~nm}$. Being irradiated under ultraviolet light, it emitted green fluorescence.

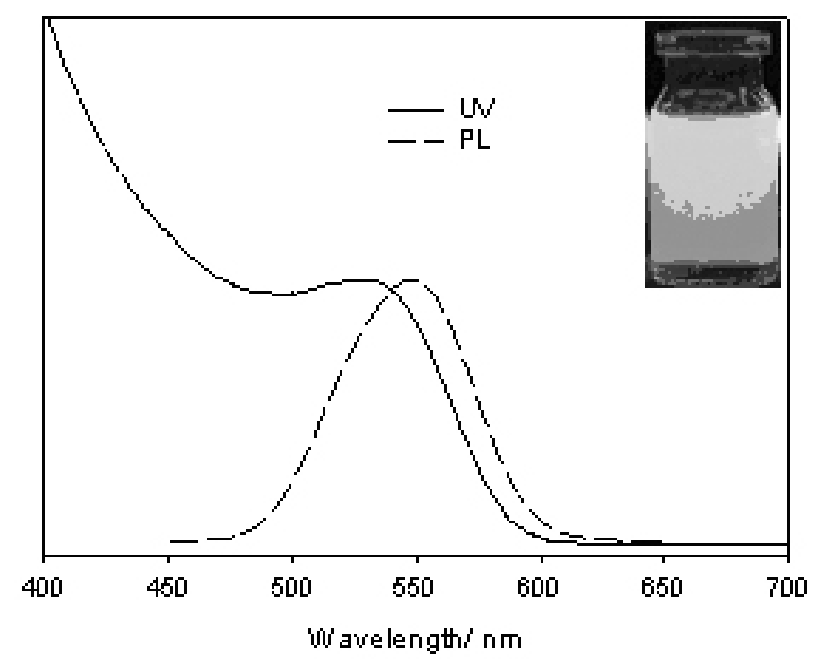

Figure 1.- Absorption and fluorescence spectra of CdTe QDs.

Figure 2 presented the FT-IR spectra of L-cysteine and CdTe capped with L-cysteine. A broad absorption band around $3400 \mathrm{~cm}^{-1}$ and an absorption band at $2900 \mathrm{~cm}^{-1}$ were assigned to O-H vibrations of the absorbed $\mathrm{H}_{2} \mathrm{O}$ and $\mathrm{C}-\mathrm{H}$ vibration in the alkyl chain of the surface modifiers, respectively. A broad absorption band at $1550-1600 \mathrm{~cm}^{-1}$ due to $\mathrm{C}=\mathrm{O}$ vibration was observed in all cases, and an absorption band at $2560 \mathrm{~cm}^{-1}$ due to S-H vibration disappeared in $\mathrm{CdTe}$ with capped L-cysteine. These revealed that L-cysteine was bound to the surface of $\mathrm{Cd}^{2+}$ site through Cd-SR bond formation.

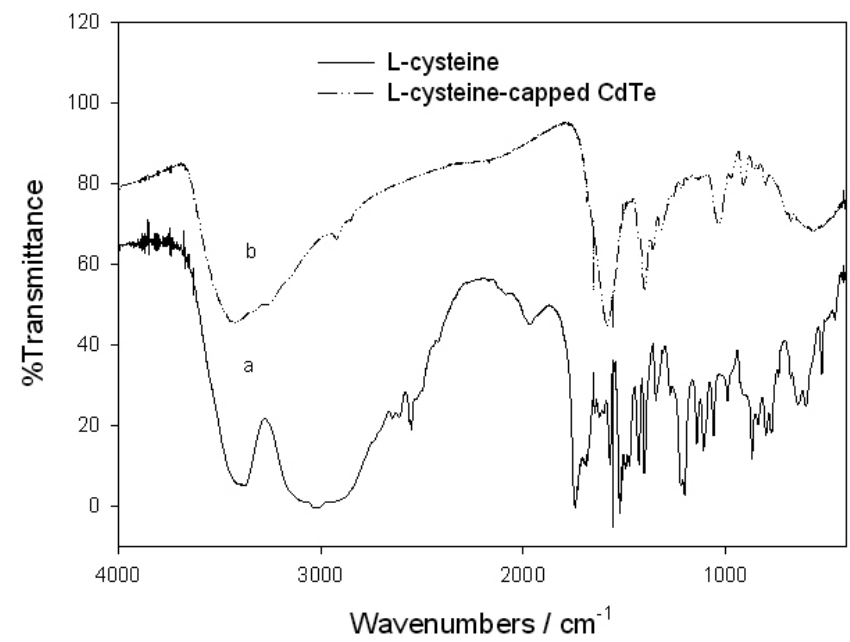

Figure 2.- FT-IR spectra of (a) L-cysteine and (b) CdTe with capped L-cysteine.

\section{Effect of $\mathrm{Cu}^{2+}$ on the fluorescence intensity of CdTe QDs}

The effect of $\mathrm{Cu}^{2+}$ on the fluorescence spectra of QDs has been investigated. As seen in Figure 3, it is evident that the fluorescence intensity of CdTe QDs decreases as the $\mathrm{Cu}^{2+}$ concentration increases. The effective quenching of the fluorescence of CdTe QDs in terms of $\mathrm{Cu}^{2+}$ ions is attributed to extremely low soluble particles of CuTe formation onto the surface of QDs in place of CdTe. For these structures, electron and hole transfer from the CdTe to the CuTe energy levels is assumed to be much faster than the process of fluorescence generation in the $\mathrm{CdTe}$, the energy of the electrons is released in non-radiative form ${ }^{18}$. As a result, the fluorescence of QDs is quenched efficiently.

Considering the quenching of fluorescence observed in the presence of ultra trace amounts of $\mathrm{Cu}^{2+}$ ions, the possibility of developing a sensitive method for determination of $\mathrm{Cu}^{2+}$ has been investigated.

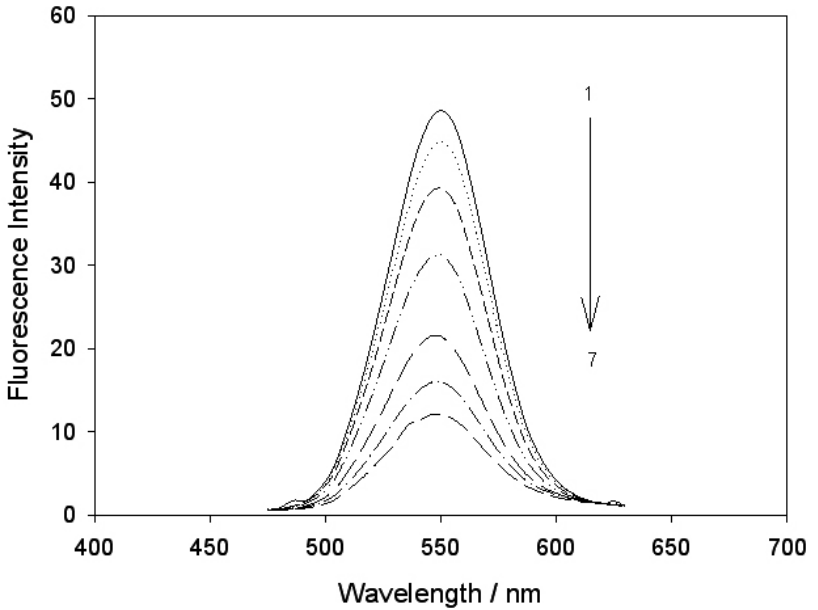

Figure 3. Fluorescence spectra of CdTe QDs in the presence of $\mathrm{Cu}^{2+}$, The concentration of QDs was $2.72 \times 10^{-7} \mathrm{~mol} \cdot \mathrm{L}^{-1}$, from top to bottom, the concentrations of $\mathrm{Cu}^{2+}$ were $0,20,40,80,160,240,300 \mu \mathrm{g} \cdot \mathrm{L}^{-1}$, respectively.

\section{Optimum conditions for determination}

The fluorescence emission spectra of QDs are sensitive to the system environment. In order to develop a sensitive and rapid spectrophotometric method for the determination of $\mathrm{Cu}^{2+}$, the experimental conditions were 
improved by studying the effect of various factors such as $\mathrm{pH}$ value, QDs concentration and incubation time.

The influence of $\mathrm{pH}$ in a range between 5.96 and 8.34 was studied in order to select the best acidity for the determination of $\mathrm{Cu}^{2+}$ with QDs. The intensity reached its maximum at $\mathrm{pH}=7.2$ as shown in Figure 4, however, $\mathrm{pH}$ values both lower and higher than 7.2 resulted in a significant decrease in the fluorescent intensity. It could be rationale that in preparation, cadmium and thiol were excessive, and the $\mathrm{pH}$ was adjusted to 11.2 , so cadmium thiol complexes were formed in the solution. When the CdTe solution becomes acidic, partial thiols and cadmium ions would be released from the cadmium thiol complexes, the particle surface covered with TGA was increased. Therefore, the trap sites on the CdTe surface would be removed, which dramatically improved the fluorescence intensity ${ }^{11}$. When $\mathrm{pH}$ value decreased too low, the thiols attached to the QDs detached from the surface, more surface defects formed, resulting in a decrease of the fluorescence intensity. Therefore, to obtain high fluorescence intensity with good precision, $\mathrm{pH}=7.2\left(1 / 15 \mathrm{~mol} \cdot \mathrm{L}^{-1} \mathrm{Na}_{2} \mathrm{HPO}_{4}-\mathrm{KH}_{2} \mathrm{PO}_{4}\right.$ buffer solution) was chosen for the further studies.

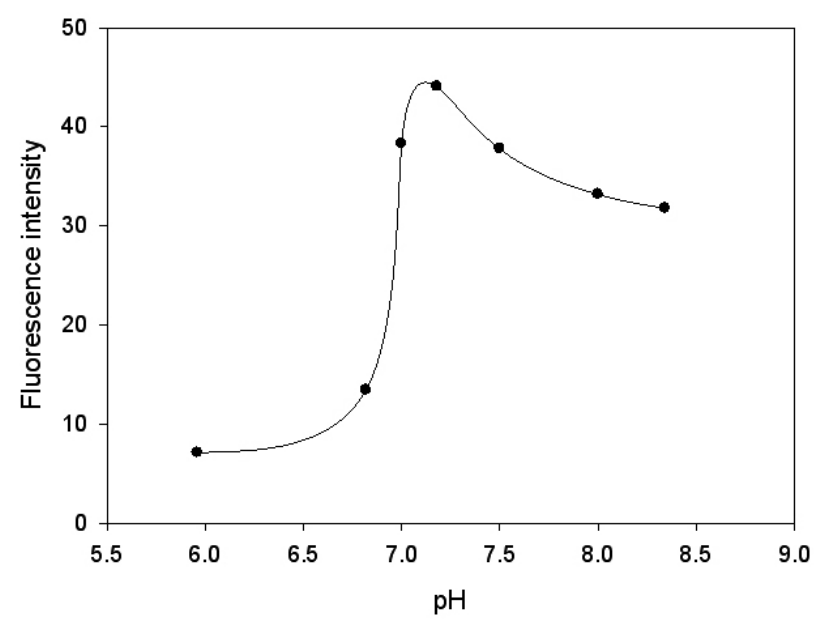

Figure 4. Effect of $\mathrm{pH}$ on the fluorescence intensity of $\mathrm{CdTe}$ capped with L-cysteine, the concentration of QDs was $2.72 \times 10^{-7} \mathrm{~mol} \cdot \mathrm{L}^{-1}$

To investigate the influence of QDs concentration on the sensitivity and linear range of determination, four calibration curves were constructed with the QDs concentrations of $1.36 \times 10^{-7}, 2.72 \times 10^{-7}, 3.40 \times 10^{-7}$ and $4.08 \times 10^{-7}$ $\mathrm{mol} \cdot \mathrm{L}^{-1}$, respectively. The results in Figure 5 showed that the linear range of calibration curve became wider on the expense of the decrease of sensitivity when the concentration of QDs increased. Therefore, for the consideration of the sensitivity and the linear range of calibration curve, $0.2 \mathrm{~mL}\left(2.72 \times 10^{-7}\right.$ $\mathrm{mol} \cdot \mathrm{L}^{-1}$ ) CdTe QDs solution was adopted.

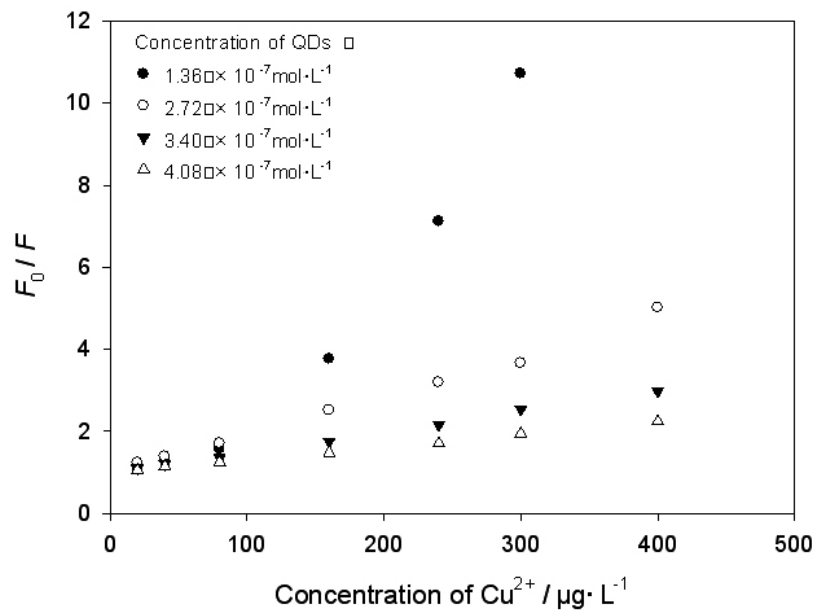

Figure 5. Effects of QDs concentration on the quenching of fluorescence
The effect of reaction times on fluorescence quenching value was also explored. After all reagents had been added, fluorescence measurement was performed every 5 minutes. It was found that the fluorescence quenching value reached the maximum after 15 minutes and kept constant in 60 minutes. Thus, fluorescence intensity was measured after the system was 15 minutes later.

The effect of other metal ions on the fluorescence intensity of the CdTe QDs was examined. As observed, $\mathrm{Hg}^{2+}$ and $\mathrm{Ag}^{+}$showed strong quenching for the QDs fluorescence intensity. It could be derived from great affinity between thiol group and "soft" metal ions. In the presence of $\mathrm{Hg}^{2+}$ or $\mathrm{Ag}^{+}$, the thiols attached to the QDs were detached from the surface, more surface defects formed, giving rise to a decrease of the fluorescence intensity. The quenching effect of $\mathrm{Fe}^{3+}$ on the fluorescence of QDs is attributed to the inner filter effect ${ }^{12}$, which can be eliminated by adding fluoride ions to form the colorless $\mathrm{FeF}_{6}{ }_{6}^{3-}$ complex. When the relative error was less than $\pm 5 \%$, the tolerance of some coexistence ions for the determination of $40 \mu \mathrm{g} \cdot \mathrm{L}^{-1} \mathrm{Cu}^{2+}$ was examined to evaluate the selectivity of the proposed method. The results showed that 200 -fold $\mathrm{Ca}^{2+}, \mathrm{Mg}^{2+}$ and $\mathrm{Al}^{3+}, 100$-fold $\mathrm{Pb}^{2+}, \mathrm{Mn}^{2+}$ and $\mathrm{Zn}^{2+}, 10$-fold $\mathrm{Co}^{2+}$ and $\mathrm{Ni}^{2+}, 5$-fold $\mathrm{Fe}^{3+}$ had no interference on the determination. Consequently, this method is applicable for the analysis of $\mathrm{Cu}^{2+}$ in biological samples.

\section{Linear equation and detection limit}

The calibration curve for determination of $\mathrm{Cu}^{2+}$ was presented in Figure 6. It was found that the fluorescence intensity of CdTe QDs quenched by $\mathrm{Cu}^{2+}$ in a relationship that was best described by a Stern-Volmer equation: $F_{0} / F$ $=K_{\mathrm{sv}}\left[\mathrm{Cu}^{2+}\right]+1$. Where, $K_{\mathrm{sv}}$ is a Stern-Volmer constant found to be $5.62 \times$ $10^{5} \mathrm{~L}^{\mathrm{sv}} \cdot \mathrm{mol}^{-1}$

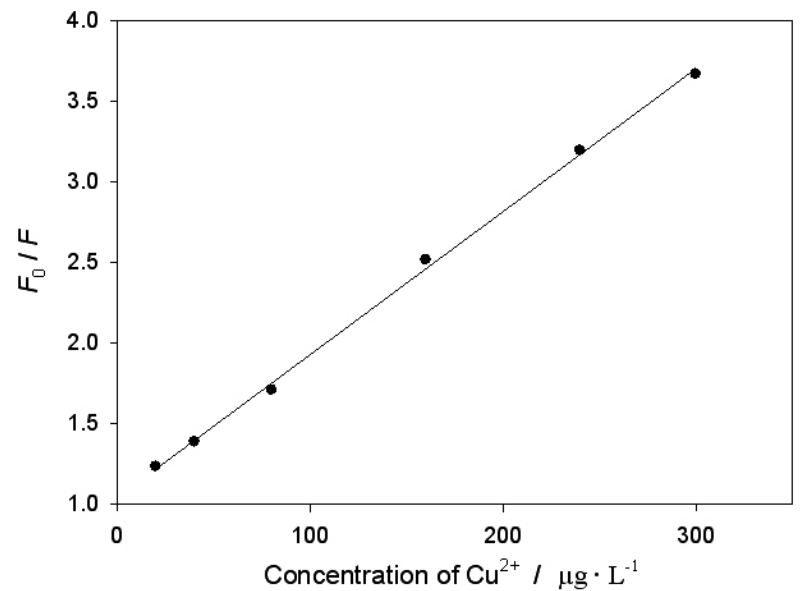

Figure 6. Stern-Volmer relationship between QDs and $\mathrm{Cu}^{2+}$ ions, the concentration of QDs was $2.72 \times 10^{-7} \mathrm{~mol} \cdot \mathrm{L}^{-1}$

The linear regression equation was $F_{0} / F=0.0088 C+1.044$, where $F_{0}$ and $F$ were the fluorescence intensity of $\mathrm{CdTe}$ QDs in the absence and presence of $\mathrm{Cu}^{2+} ; C$ was the concentration of $\mathrm{Cu}^{2+}$, the unit was $\mu \mathrm{g} \cdot \mathrm{L}^{-1}$. The linear range was from 20 to $300 \mu \mathrm{g} \cdot \mathrm{L}^{-1}$ with a correlation coefficient of 0.998 . The limit of detection (LOD) $9.3 \mu \mathrm{g} \cdot \mathrm{L}^{-1}$ and limit of quantification (LOQ) $44.0 \mu \mathrm{g} \cdot \mathrm{L}-$ ${ }^{1}$ were calculated from $3.52 \sigma_{\mathrm{B}}$ and $16.67 \sigma_{\mathrm{B}}{ }^{25}$, respectively. The relative standard deviation (RSD) for five replicate determinations was $3.6 \%$ for a $\mathrm{Cu}^{2+}$ concentration of $40 \mu \mathrm{g} \cdot \mathrm{L}^{-1}$, suggesting one of the most sensitive methods for the determination of $\mathrm{Cu}^{2+}$.

\section{Analytical performance}

The developed method has been applied to the determination of copper in real samples of hair and tea. A suitable volume of sample solution was added to a $10.0 \mathrm{~mL}$ colorimetric tube, the content of $\mathrm{Cu}^{2+}$ was determined according to the proposed technique. The results were presented in Table 1. The contents of copper determined in these samples are in good agreement with those obtained by ICP-AES method. 
Table1.- Analytical results of samples $(n=5)$

\begin{tabular}{|l|c|c|c|c|}
\hline Samples & Found $\left(\mu \mathrm{g} \cdot \mathrm{g}^{-1}\right)$ & Average $\left(\mu \mathrm{g} \cdot \mathrm{g}^{-1}\right)$ & RSD $(\%)$ & ICP-AES $\left(\mu \mathrm{g} \cdot \mathrm{g}^{-1}\right)$ \\
\hline Hair & $8.37,8.29,8.53,8.41,8.48$ & 8.42 & 1.1 & 8.16 \\
\hline Tea & $13.9,14.1,14.5,14.2,14.3$ & 14.2 & 1.6 & 13.5 \\
\hline
\end{tabular}

\section{CONCLUSIONS}

CdTe QDs capped with L-cysteine were synthesized in aqueous solution, and a novel method for the determination of $\mathrm{Cu}^{2+}$ was developed based on its fluorescence quenching for the QDs. Under the optimum conditions, calibration curve was linear in the range of $20 \sim 300 \mu \mathrm{g} \cdot \mathrm{L}^{-1}$ with the correlation coefficient of 0.998 , the detection limit of $\mathrm{Cu}^{2+}$ was $9.3 \mu \mathrm{g} \cdot \mathrm{L}^{-1}$. Furthermore, the feasibility of the method has been proven by the determination of trace copper in hair and tea samples with satisfactory results.

\section{ACKNOWLEDGEMENT}

Financial support from the scientific research fund of Guangxi University (No. X081057) is gratefully acknowledged.

\section{REFERENCES}

1 M. J. Bruchez, M. Moronne, A. P. Alivisatos, et al. Science, 281, 2013, (1998)

2 C. W. Warren, S. M. Nie. Science, 281, 2016, (1998)

3 Z. A. Peng, X. G. Peng. J. Am. Chem. Soc, 123,183, (2001)

4 D. V. Talapin, A L Rogach, H. Weller, et al. Nano Lett, 1, 207, (2001)

5 N. L. Gaponik, D. V. Talapin, H. Weller, et al. J. Phys. Chem B, 106, 7177, (2002)

6 N. Pradhan, D. Goorskey, X. G. Peng, et al. J. Am. Chem. Soc, 127, 17586, (2005)

7 J. K. Jaiswal, H. Mattoussi, J. M. Mauro, et al. Nature biotechnology, 21, 47, (2003)
8 X. H. Gao, Y. Y. Cui, S. M. Nie, et al. Nature biotechnology, 22, 969 , (2004)

9 L. Spanhel, M. Haase, A. Henglein, et al. J. Am. Chem. Soc, 109, 5649, (1987)

10 D. Diaz, J. N. Robles, N. Kotov, et al. J. Phys. Chem B, 103, 9859 , (1999)

11 M. Y. Gao, S. Kirstein, H. Weller, et al. J. Phys. Chem B, 102, 8360, (1998)

12 Y. F. Chen, Z. Rosenzweig. Anal. Chem, 74, 5132, (2002)

13 M Kerim, A Gattas, M Roger, et al. Chemcomm, 38, 2684, (2003)

14 Z. X. Cai, H. Yang, Y. Zhang, X. P. Yan. Analytica Chimica Acta, 559, $234,(2006)$

15 J. L. Chen, C. Q. Zhu. Analytica Chimica Acta, 546, 147, (2005)

16 H. M. Wu, J. G. Liang, H. Y. Han. Microchim Acta,161, 81, (2008)

17 Y. S. Xia, C. Q. Zhu. Talanta, 75, 215, (2008)

18 H. Y. Xie, J. G. Liang, Z. L. Zhang, et al. Spectro chimica Acta Part A, 60, 2527, (2004)

19 T. F. Maria, W. J. Jin, S. M. Alfredo, et al. Analytica Chimica Acta, 549, $20,(2005)$

20 Y. H. Zhang, H. S. Zhang, X. F. Guo, et al. Microchemical Journal, 89,142, (2008)

21 H. Zhang, Z. Zhou, B.Yang, M.Y. Gao. J.Phys.Chem.B, 107, 8, (2003)

22 L.D. Klayman, T.S. Griffin. J. Am. Chem. Soc., 95, 197, (1973)

23 G. W. Zhang, H. Zhang, Y. H. Liu. Spectroscopy and Spectral Analysis, 17, 74, (1997)

24 W. W. Yu, L. H. Qu, W. Z. Guo, et al. Chem. Mater, 15, 2854, (2003)

25 L. Currie. Analytica Chimica Acta, 391, 105, (1999) 